\title{
Tingkat Kerusakan dan Serangan Hama Buah Lada, Dasynus piperis China pada Pertanaman Lada di Bangka
}

\author{
I W. Laba, D. Kilin dan I M. Trisawa \\ Balai Penelitian Tanaman Rempah dan Obat \\ jl. Tentara Pelajar Noo. 3 Bogor 16114
}

\begin{abstract}
Berry sucker insect pest, Dagyas piptris china (coreidae; Hemiptera) is one of the major insect pest on pepper. D. pipens to attack frut of pepper with suck of fruir liquid and the final effect is empty to fruir and damaged. To find out of the level of damige and destruction caused by D. piptris have been done at 6 districts of Bangka Island namely Mendo Barar, Sungai Selan, Sungai Liat, Belinru, Koba and Toboali since January to December 2002. For each distnct were observed 5 farmers field of estare crops. Every farmer field were observed tens plant of pepper in connection with fluctuation population and level of frut damage. The observation have been done on the flower season of pepper, after flower season and after harvest. The result showed that flucruation population and infested level of $D$. piperis at each observation almost the same, while among district were vanated. The highest infestation was found in Sungai Selan, followed by Belinyu, and Mendo Barat namely $36.82 ; 32.03$ and $29.48 \%$ respecrively. The infestation level on Sungai Liar, Toboali and Koba were low namely $14 ; 19.58$ and $20.98 \%$ respectively. The level of damage in Nendo Barat was highest than an other location namely 8.66; 8.07; $6.67 ; 5.11 ; 4.89$ and $3.09 \%$ in Mendo Barat, Sungai Selan, Belinju, Koba, Toboali and Sungai Liat respectively.
\end{abstract}

Key words : Dagnas piperis, level of infestation, level of damage, pepper, Bangka.

\section{PENDAHULUAN}

Produksi lada di Indonesia masih rendah (kurang dari 1 ton/ha) dibandingkan Malaysia (2,6 ton $/ \mathrm{Ha})$ dan Brazil (3,2 ton/Ha). Salah satu faktor pembatas produktivitas tersebut adalah serangan hama dan patogen penyakit (Balittro, 1997). Hama yang menyerang lada di Indonesia adalah penggerek batang (Lophobaris piperis Marsh.), penghisap bunga (Diconocoris bewetti Dist.) dan penghisap buah (Dasynus piperis China). Penggerek batang dan penghisap buah dijumpai hampir di seluruh daerah pertanaman lada.
Kepik D. piperis tergolong dalam ordo Hemiptera dan famili Coreidae. Kepik bewarna hijau kecoklatan, dewasanya berukuran panjang 10-15 mm, lebar 4-5 mm dan mempunyai tipe mulut menusuk dan mengisap. Kepik dewasa dapat hidup \pm 3 bulan. Siklus hidup dari telur hingga serangga dewasa sekitar 6 minggu. Serangga dewasa betina selama hidupnya dapat menghasilkan telur \pm 200 butir (Direktorat Bina Perlindungan Tanaman, 1994). Menurut Kalshoven (1981), kepik betina meletakkan telur secara berkelompok. Jumlah telur setiap kelompok berkisar antara 3-10 butir. Produksi telur maksimal 160 butir. 
Kepik betina dewasa akan bertelur selama \pm 14 hari. Serangga dewasa dapat hidup sampai 1-3 bulan, namun siklus hidup secara keseluruhan rata-rata berlangsung 1,5-2 bulan. Chapmann (1971) menyatakan bahwa buah lada yang cukup tua (6-9 bulan) mengandung karbohidrat lebih tinggi dan dibutuhkan untuk pertumbuhan kepik secara optimal.

Berdasarkan hasil survei Asnawi (1992), tingkat kerusakan buah oleh kepik berkisar antara 14,72-16,01\%. Serang-an paling berat dijumpai di Bangka Tengah (23-36\%), kemudian di Bagian Utara dan Barat (19-22\%), sedangkan di Bangka Selatan serangan agak ringan (15-17\%). Pola tanam dan agroekosistem pada seluruh areal relatif sama.

Kerusakan buah yang terserang $D$. piperis pada umumnya melihat kerusakan tandan buah. Satu tandan terakhir dalam satu tandan sudah dihitung seluruh tandan terserang (rusak), padahal dalam satu tandan terdiri dari banyak buah (10-75 buah). Untuk menentukan kerusakan buah lada diperlukan teknik pengamatan, dengan melihat fluktuasi populasi dan menghitung buah yang rusak (terserang) D. piperis. Hasil penelitian ini diharapkan dapat digunakan untuk menentukan tingkat kerusakan buah lada yang terserang D. piperis.

\section{BAHAN DAN METODE}

Penelitian menggunakan metode survei wilayah yang disurvei adalah pulau Bangka. pada tahun 2001-2002.
Mempertimbangkan potensi serangan yang ada, penentuan contoh dilakukan berjenjang dimana wilayah pertanaman lada dibagi atas tiga kategori yaitu (1) daerah serangan tinggi, (2) daerah serangan sedang dan (3) daerah serangan rendah. Penentuan daerah serangan didasarkan atas data pada tiap kecamatan menurut Statistik Perkebunan (Dinas Perkebunan) yang diplotkan pada peta pulau Bangka. Penentuan lokasi didasarkan atas posisi kecamatan pada wilayah sebar dan setiap kategori kecamatan dipilih lima kebun yang mewakili kategori kecamatan tersebut. Contoh untuk pengamatan D. piperis adalah tanaman. Populasi unit contoh untuk setiap kebun adalah 10 pohon. Pengamatan dilakukan terhadap populasi $D$. piperis pada ketinggian 1,5 $\mathrm{m}$ diatas permukaan tanah. Pengamatan dilakukan pada awal musim bunga, awal musim panen dan akhir musim panen.

Data yang dikumpulkan adalah populasi $D$. piperis, kerusakan buah pertandan, kerusakan tandan buah perpohon. Setiap pohon diambil dua tandan buah secara acak, sehingga jumlah sampel dalam satu kebun adalah 20 tandan. Tingkat kerusakan tandan buah per pohon ditentukan melalui 4 arah mata angin (Timur, Utara, Barat dan Selatan) setinggi $1,5 \mathrm{~m}$ dpt. Selanjutnya dihitung jumlah serangga per pohon. Disamping itu juga, diamati hama bunga dan penggerek batang. 


\section{HASIL DAN PEMBAHASAN}

Hama yang ditemukan di lapangan adalah hama pengisap buah lada ( $D$. piperis), pengisap bunga (D. bewett $)$ dan penggerek batang ( $L$ piperis) (Gambar 1 , 2 dan 3). Hama penggerek batang dan hama bunga menyebar di semua keca- matan. Jumlah cabang yang terserang $L$ piperis pada bulan Juli 2002 (pengamatan II) berkisar antara 5,4-11 cabang per kebun. Pada pengamatan Mei dan Oktober (pengamatan I dan III) tidak ditemukan gejala serangan penggerek batang. Hal ini kemungkinan karena pada pengamatan I serangga penggerek ba-

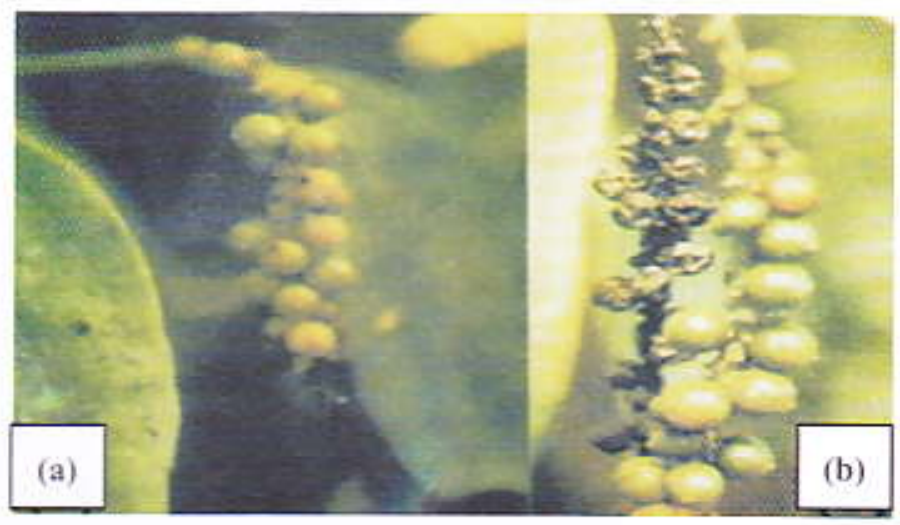

Gambar 1. Gejala kerusakan buah akibat serangan hama pengisap buah (a) ringan; (b) berat

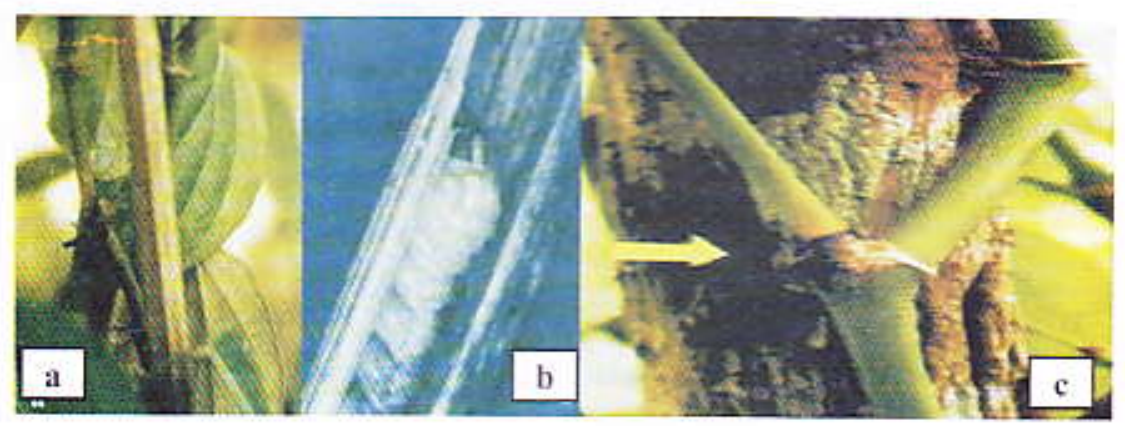

Gambar 2. Hama pengisap bunga (a) gejala serangan; (b) larva penggerek di daiam cabang lada; (c) gejala serangan awal penggerek batang lada
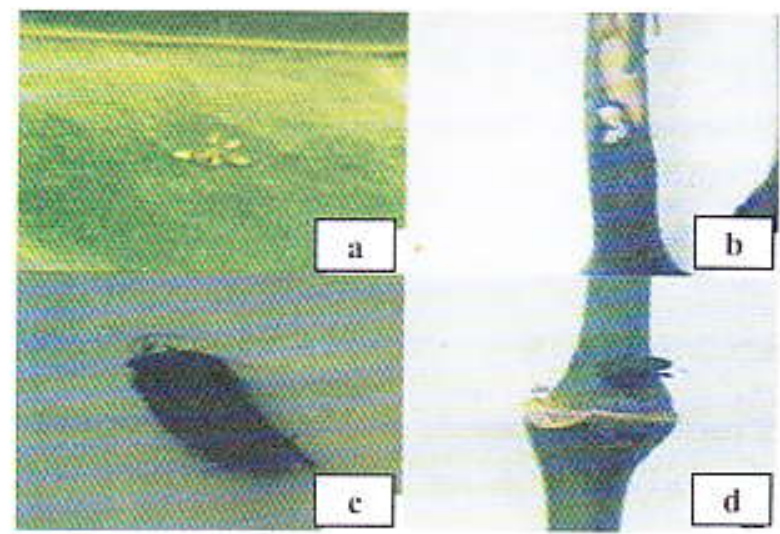

Gambar 3. Bentuk stadia L. piperis (a) telur; (b) Larva: (c) Pupa; dan (d) imago 
tang yang berada di dalam batang belum menunjukkan gejala, sedangkan pada pengamatan yang ketiga ranting dan cabang banyak yang kering dan rontok karena kemarau panjang sehingga tidak ditemukan gejala serangan penggerek batang. Meskipun tingkat serangan relatif rendah, keberadaan penggerek batang harus diwaspadai karena sangat merugikan. Serangan larvanya dapat mengakibatkan kematian tanaman. Bagian tanaman yang mengalami gerekan akan mudah patah karena rapuhnya bagian dalam cabang atau batang terserang.

Tingkat serangan hama bunga bervariasi pada setiap pengamatan. Tingkat serangan tertinggi terdapat di kecamatan Sungai Selan, kemudian diikuti oleh
Koba, Toboali dan Mendo Barat. Pada pengamatan kedua populasi hama bunga pada semua lokasi meningkat, berkisar antara 4,62-23,68\%. Pada pengamatan ketiga populasi atau tingkat serangan hama bunga menurun pada semua kecamatan yang diamati kecuali di Mendo Barat. Rendahnya tingkat serangan hama bunga pada pengamatan ketiga karena bunga lada sudah menjadi buah. Hal ini menunjukkan bahwa fluktuasi populasi hama bunga sangat bergantung dari keberadaan bunga (Tabel 1). Tingkat serangan di Mendo Barat tetap tinggi karena bunga lada masih banyak terdapat di lapangan.

Tingkat serangan hama buah lada juga bervariasi pada tiap lokasi yang di-

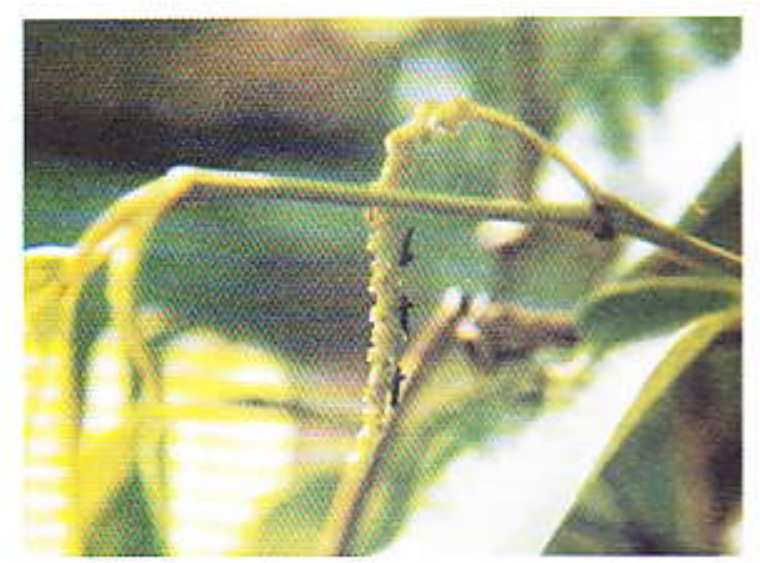

Gambar 3. Serangga dewasa hama perusak bunga ( $L$ piperis)

Tabel 1. Tingkat serangan $(\%)$ hama bunga lada, $D$. hewetti Dist. di beberapa kecamatan di Bangka 2002

\begin{tabular}{cccc}
\hline \hline & & \multicolumn{3}{c}{ Waktu pengamatan } \\
\cline { 2 - 4 } No. Kecamatan & Mei & Juli & Oktober \\
\hline 1. Sungai Selan & $21,88 \mathrm{a}$ & $23,68 \mathrm{a}$ & $2,26 \mathrm{~b}$ \\
2. Koba & $13,7 \mathrm{~b}$ & $20 \mathrm{a}$ & $6,07 \mathrm{ab}$ \\
3. Toboali & $10,0 \mathrm{~b}$ & $20 \mathrm{a}$ & $6,66 \mathrm{ab}$ \\
4. Sungai Liat & $2,53 \mathrm{c}$ & $4,62 \mathrm{C}$ & $1,4 \mathrm{~b}$ \\
5. Belinyu & $2,2 \mathrm{C}$ & $6,79 \mathrm{bc}$ & $1,23 \mathrm{~b}$ \\
6. Mendo Barat & $8,88 \mathrm{bc}$ & $12,41 \mathrm{~b}$ & $12,25 \mathrm{a}$ \\
\hline
\end{tabular}

Keterangan: Angka yang diikuti huruf yang sama dalam setiap kolom tidak berbeda nyata berdasarkan DMRT pada taraf $5 \%$ 
amati, sedangkan fluktuasi populasi dan tingkat serangan pada setiap kali pengamatan relatif sama. Serangan tertinggi terdapat di kecamatan Sungai Selan, kemudian diikuti oleh kecamatan Koba dan Mendo Barat. Populasi hama buah lada kelihatannya menunjukkan korelasi positif dengan persentase kerusakan buah lada khususnya pada pengamatan I dan II (Mei dan Juli) D. piperis sangat rendah. Pada waktu pengamatan hama ini cepat sekali berpindah tempat dari satu pohon ke pohon lainnya (Gambar 4 dan Tabel 2).

Gambar 4 menunjukkan bahwa semakin tinggi populasi hama buah lada, tingkat kerusakan buah meningkat. Khusus pada pengamatan III (Oktober) menunjukkan bahwa hama buah menurun kerusakan meningkat, hal ini karena pada bulan Oktober sudah panen yang kedua, sehingga populasi D. piperis sangat rendah, sedangkan kerusakan tetap terjadi akibat serangan pada bulan sebelumnya.

Hubungan antara persentase kerusakan tandan dengan kerusakan bulir lada menunjukkan bahwa tingkat kerusakan tandan lebih besar dibandingkan dengan kerusakan bulir lada. Suatu contoh di Kecamatan Sungai Selan tingkat kerusakan tandan pada bulan Mei

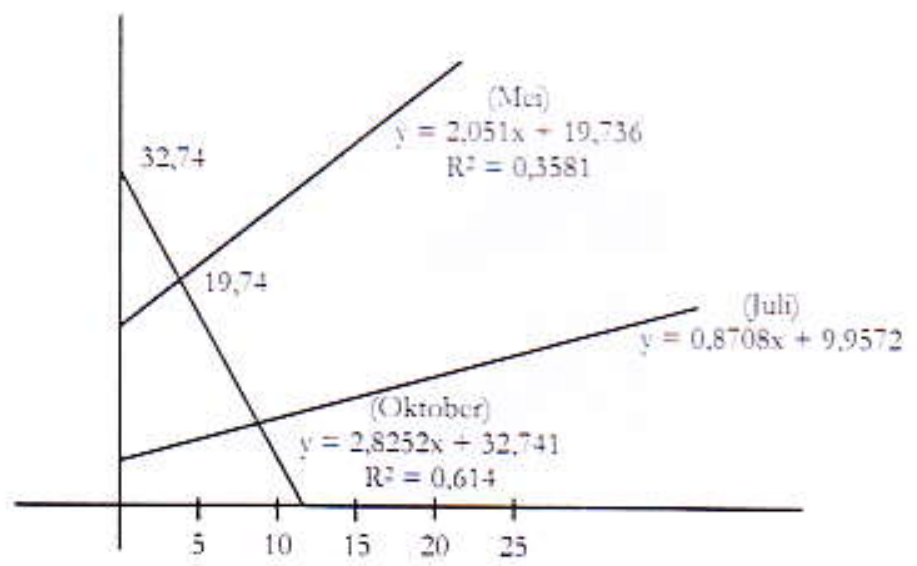

Gambar 4. Hubungan kerusakan tandan dengan populasi $D$. piperis

Tabel 2. Tingkat serangan dan populasi per kebun hama buah lada, $D$. piperis di beberapa kecamatan di Bangka 2002.

\begin{tabular}{llcccccc}
\hline \hline & \multicolumn{6}{c}{ Waktu pengamatan } \\
\cline { 2 - 7 } No. Kecamatan & \multicolumn{2}{c}{ Mei } & \multicolumn{2}{c}{ Juli } \\
\cline { 2 - 7 } & $\begin{array}{c}\text { Tingkat } \\
\text { serangan (\%) }\end{array}$ & $\begin{array}{c}\text { Populasi } \\
\text { (ekor) }\end{array}$ & $\begin{array}{c}\text { Tingkat } \\
\text { serangan (\%) }\end{array}$ & $\begin{array}{c}\text { Populasi } \\
\text { (ekor) }\end{array}$ & $\begin{array}{c}\text { Tingkat } \\
\text { serangan (\%) }\end{array}$ & $\begin{array}{c}\text { Populasi } \\
\text { (ekor) }\end{array}$ \\
\hline 1. Sungai Selan & $36,82 \mathrm{a}$ & 4,2 & $26,06 \mathrm{a}$ & 17,2 & $33,11 \mathrm{a}$ & 2,2 \\
2. Koba & $20,98 \mathrm{~b}$ & 0,8 & $13,33 \mathrm{bc}$ & 1,6 & $24,23 \mathrm{~b}$ & 0.8 \\
3. Toboali & $19,58 \mathrm{~b}$ & 4,0 & $11,84 \mathrm{bc}$ & 7,5 & $25,54 \mathrm{~b}$ & 1,8 \\
4. Sungai Liat & $14,00 \mathrm{~b}$ & 0,2 & $7,30 \mathrm{c}$ & 3,0 & $16,24 \mathrm{c}$ & 4,6 \\
5. Selinyu & $32,03 \mathrm{a}$ & 6,6 & $16,27 \mathrm{~b}$ & 3,6 & $31,73 \mathrm{ab}$ & 2,0 \\
6. Mendo Barat & $29,48 \mathrm{a}$ & 1,0 & $17,60 \mathrm{~b}$ & 4,6 & 28,3 ab & 1,8 \\
\hline
\end{tabular}

Keterangan: Angka yang dikuti huruf yang sama dalam setiap kolom tidak berbeda nyata berdasarkan DMRT pada taraf $5 \%$ 
$36,82 \%$, kenyataan kerusakan bulir lada hanya $9,59 \%$. Hal ini juga terjadi/ berlaku pada hasil pengamatan di kecamatan lainnya. Hubungan antara kerusakan bulir dan kerusakan tandan menunjukkan korelasi positif, semakin tinggi kerusakan bulir, maka akan semakin tinggi kerusakan tandan (Tabel 3 dan Gambar 5). Kerusakan bulir lebih tepat dibandingkan dengan kerusakan tandan, karena tandan terserang tidak menunjukkan seluruh butiran rusak.

Kecenderungan hasil panen per pohon menunjukkan bahwa semakin tinggi tingkat serangan, maka hasil panen semakin rendah, walaupun rendahnya produksi bukan hanga ditentukan oleh D. piperis, tetapi juga oleh hama lainnya, budidaya petani, varietas lada dan umur tanaman lada serta ringkat kesuburan tanah.

Gambar 5 menunjukkan bahwa hubungan tingkat kerusakan tandan dan bulir/tandan pada bulan Mei, Juli dan Oktober 2002 berbeda. Perbedaan kerusakan antara metode pengamatan tandan dan bulir paling rendah pada pengamatan bulan Juli, sedangkan selisih tertinggi terdapat pada bulan Oktober 2002 artinya semakin tinggi persentase kerusakan tandan dikuri oleh kerusakan bulir, tetapi laju kerusakan bulir tidak sebanding dengan kerusakan tandan. Laju kerusakan bulir pada bulan Mei dan Juli lebih tinggi dibandingkan pada pengamatan bulan Oktober.

Tabel 3. Tingkat serangan $D$. piperis, butir buah yang rusak dan hasil panen di beberapa kecamatan di Bangka 2002

\begin{tabular}{|c|c|c|c|c|c|c|c|c|c|c|}
\hline \multirow{2}{*}{ No. } & \multirow{2}{*}{ Kecamatan } & \multicolumn{3}{|c|}{$\begin{array}{c}\text { Tingkat serangan } \\
\text { tandan }\end{array}$} & \multirow{2}{*}{$\begin{array}{l}\text { Rata- } \\
\text { rata }\end{array}$} & \multicolumn{3}{|c|}{ Bulir buah yang rusak (\%) } & \multirow{2}{*}{$\begin{array}{l}\text { Rata- } \\
\text { rata }\end{array}$} & \multirow{2}{*}{$\begin{array}{c}\text { Hasil panen } \\
\text { per pohon } \\
\text { (gram) }\end{array}$} \\
\hline & & Mei & Juli & Okt & & Mei & Juli & Okt & & \\
\hline 1. & Sungai Selan & 36,82 & 26,06 & 33.11 & 31.99 & 9,59 & 10,3 & 4,33 & 8.07 & 210 \\
\hline 2. & Koba & 29,98 & 13,33 & 24,23 & 19.51 & 5,81 & 6,1 & 3,43 & 5,11 & 860 \\
\hline 3. & Toboali & 19,98 & 11.84 & 25,54 & 18,99 & 5.33 & 6,1 & 3,23 & 4,89 & 710 \\
\hline 4. & Sungai Liat & 14,00 & 7,30 & 16.24 & 12,51 & 3.39 & 2,7 & 3,18 & 3,09 & 570 \\
\hline 5. & Belinyu & 32,03 & 16,27 & 31.73 & 26,68 & 9.61 & 5,1 & 5,30 & 6,67 & 465 \\
\hline 6. & Mendo Barat & 29,48 & 17,60 & 28,3 & 25.13 & 10,10 & 11,1 & 4,77 & 8,66 & 170 \\
\hline
\end{tabular}

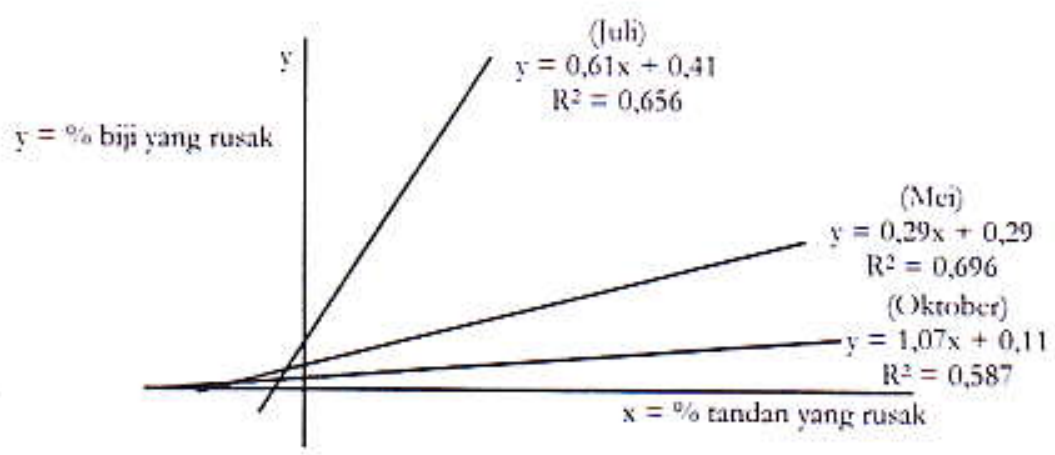

Gambar 5. Hubungan kerusakan tandan/pohon dengan kerusakan biji/tandan 


\section{KESIMPULAN}

Tingkat serangan penggerek batang L piperis sangat rendah, hanya 5,411 cabang terserang per kebun. Tingkat serangan hama pengisap bunga $D$. betwetti tertinggi $23,68 \%$ terdapat di kecamatan Sungai Selan, sedang di Sungai Liat dan Belinyu rendah.

Tingkat serangan pengisap buah lada D. piperis bervariasi dari tiap kecamatan, sedangkan fluktuasi populasi dan tingkat serangan dari tiap pengamatan relatif sama. Serangan tertinggi $(36,82 \%)$ terdapat di kecamatan sungai selan, sedang terendah di kecamatan Sungai Liat. Kerusakan tandan oleh $D$. piperis selalu lebih besar dibanding kerusakan bulir lada, dan keduanya berkorelasi positif.

\section{DAFTAR PUSTAKA}

Asnawi, Z. 1992. Sebaran Hama Ltama di Daerah Sentra Produksi Lada (Piper nigrum L.) di Bangka. Laporan Hasil Penclitian Balai Penelitian Tanaman Rempah dan Obat (tidak dipublikasikan).

Balittro, 1997. Evaluasi hasil dan pemantapan program penelitian hama dan penyakit secara terpadu pada beberapa tanaman rempah dan obat. Evaluasi pemantapan PHT ranaman perkebunan. Bogor, 23-24 April.

Chapman, R.F. 1971. The insect structure and function. The English Univ. Press, London. $116 \mathrm{p}$.

Decivanto, S. 1991. Fluctuation of pepper bug (Dasynus piperis China) population in Bangka. Indst. Crops. Res. J. 3(2):27-30.

Direktorat Bina Perlindungan Tanaman, 1994. Buku Operasional Pengendalian Hama Pengisap Buah Lada Dasws piperis China. Direktorat Bina Perlindungan Tanaman, Departemen Pertanian Jakarta.

Kalshoven, L.G.E. 1981. Pest of Crops in Indonesia. PT. Ichtiar Bart van Hoeve, Jakarta. $701 \mathrm{pp}$.

Karmawati, E. 1988, Metode pendugaan populasi pengisap buah lada secara beruntun di Kabupaten Bangka. Pemberitaan Penelitan Tanaman Industri. 13(3-4):69-75.

Mustika, 1., D. Soctopo dan D. Manohara. 1998. Lada (Piper ntgram L.) Dalam Pedoman Pengendalian Hama Terpadu Tanaman Perkebunan. Pusat Penelitian dan Pengembangan Tanaman Industri. Bogor. $72-73$ hal.

Suprapto, Suroso dan Z. Asnawi. 1996. Status inang pengisap buah (Dasnus piperis China) pada cabai jawa (Piper nitrofractum L.) Jumal Penelitian Tanaman Industri. 1(2)L :84-88. 